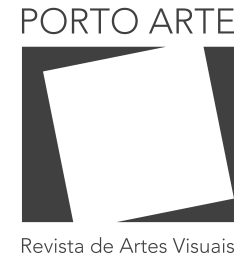

v.25n. 44 $\mathrm{Jul} / \mathrm{dez} 2020$ e-ISSN: 2179-8001

\title{
BAPHORAU - A arte como cuidado, saúde e ciência
}

"BAPHORAU - Art as care, health and science"

\section{Michel de Oliveira Furquim,}

ORCID: 0000-0003-0083-5924

Universidade de São Paulo, Brasil

\section{Dulce Meire Mendes Morais}

ORCID: 0000-0001-5896-2593

Universidade de São Paulo, Brasil

\section{Maria Clara Elias Polo}

ORCID: 0000-0002-3968-7247

Universidade de São Paulo, Brasil

José Miguel Nieto Olivar

ORCID: 0000-0002-7648-7009

Universidade de São Paulo, Brasil

\section{Resumo}

O trabalho apresenta a experiência do BAPHORAU, evento produzido pelo coletive da Faculdade de Saúde Pública, como proposta de pensar, refletir e reimaginar as práticas e os discursos da/na saúde. Os saberes de corpes que são historicamente negligenciados por parte do discurso da biomédico, se apresentam como protagonistas no evento que se propõem a pensar a saúde a partir de expressões artísticas e novas formas de diálogo com a sociedade. E o BAPHORAU se mostrou como um respiro em tempos de COVID-19, possibilitou homenagear os mortos deste período e criar novas redes de cuidado.

Palavras-chave

Baphorau. Saúde pública. Cuidado. Internet. Evento.

\section{Abstract}

The work presents the experience of BAPHORAU, event produced by the collective of the College of Public Health, as a proposal to think, reflect and reimagine the practices and discourses of/in health. The knowledge of bodies that are historically neglected by the biomedical discourse, are presented as protagonists in the event that propose to think about health from artistic expressions and new forms of dialogue with society. And BAPHORAU showed itself as a breath in times of COVID-19, made it possible to honor the dead of this period and create new care networks. 


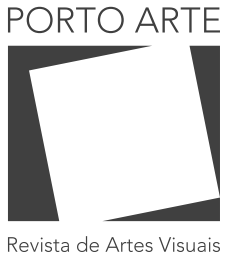

$\vee 25 n .44$ $\mathrm{Jul} / \mathrm{dez} 2020$ e-ISSN: 2179-8001
É excitante pensar, escrever, conversar sobre, e criar arte que reflete um compromisso com a cultura popular, porque muito possivelmente este seja 'a' localização central futura das lutas e resistência, um lugar de encontro onde acontecimentos novos e radicais possam ocorrer. (HOOKS, 1990)

\section{Introduzindo o bafo}

Reunião no dia 05 de agosto de 2019. 0 café é péssimo, mas quente o suficiente para esquentar a garganta na tarde fria e seca paulistana. À mesa tínhamos mais alguns quitutes, que aliás não raramente roubavam o protagonismo das reuniões daquele grupo de "humanas". Ainda rastejávamos pelos corredores da Faculdade de Saúde Pública (FSP), tentando encontrar nossos lugares. Será que um grupo tão desajustado teria lugar num prédio tão afonsino?

Essa reunião particularmente tinha como foco encontrar um nome para aquele grupo que havia se formado, quase que por acidente. Aqueles acidentes estrondosos, como a queda de um imenso jatobá ou a queda de uma sanfona do alto da escada. Esse grupo teve como ponto de ancoragem em comum o antropólogo José Miguel Nieto Olivar, que sugeriu a criação de um grupo de pesquisa, que buscasse estudar a saúde pública, mas de um referencial antropológico. Foi dele também a proposta da reunião para a criação de um nome para o grupo. Éramos um grupo de pesquisa em "Antropologia" (ou era o que achávamos ser), mesmo que quase todas ali vinham de áreas da "Saúde". Uma relação bem improvável, quase inconcebível.

Não éramos apenas um Grupo, éramos também um Corpo, um Coletivo, construído com muito Café, Comida, Cuscuz e Caos. Era isso. Quase como o Super Amigos na Sala da Justiça, tínhamos agora uma alcunha para nos representar. 0 Coletivo de Pesquisa em Antropologia e Saúde (CPaS), que ajustaria seu nome para Coletive, afinal a binariedade no gênero da palavra também era uma coisa a se desconstruir. Com o nome escolhido, uma das primeiras propostas era realizar um evento, "ensaio", para uma "Feira Ciborgue" que ocorreria em 2020.

Este coletive era formade por mulheres, pretas, bixas, não-bináries e representantes de alguns outros grupos considerados minoritários, e suas integrantes tinham trabalhos individuais que já buscavam pensar a saúde e suas práxis para além das pragmáticas estruturantes da "saúde". Esta foi uma das razões que motivou o grupo a pensar num evento que não se parecesse com os eventos que eram vistos na faculdade. Por que a produção de saberes só era reconhecida em textos científicos, dentro de normas acadêmicas e geralmente produzidas por professores/doutores? E o que faziam os estudantes quando não estavam escrevendo algo para a universidade? Existia algo para além daquelas paredes uspianas (onde não se pode nem colar um cartaz ou fotografia)?

Esse evento, ensaio, que tentava incitar reflexões críticas sobre a colonialidade dos saberes na/da saúde (RESTREPO; ROJAS, 2010) também precisava de um nome. 


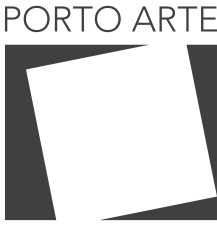

Revista de Artes Visuais

v. 25 n. 44

Jul/dez 2020 e-ISSN: 2179-8001

Sem dúvida alguma, esse encontro teria como foco as produções "extra" acadêmicas, que muitas vezes ficam limitadas a categoria de "extensão". A proposta então se aproximava de um sarau. Era isso! Seria um sarau. Com todas as ideias e propostas que tínhamos em mente - que nem todas seriam viáveis, ou seriam possíveis -, esse sarau seria bafo! Um sarau bapho. Baphônico. E assim a criança feia, preta, bixa e monstruosa foi parida. E chamaram de Baphorau.

Com o objetivo de apresentar formas artísticas de saber, cuidado e saúde no e do corpo, para além das normas acadêmico-científicas mais tradicionais, em 2019 , foi realizado a primeira versão do evento. Com poesias escritas por amadores, com exposição de fotos realizadas sem a técnica da área, com danças produzidas por não bailarinos (pelo menos não profissionalmente), entre diversas outras atividades. Buscávamos provocar a produção de conhecimento hegemônica da universidade. Paralelamente, as pesquisas de algumas integrantes do coletive também buscavam trazer para a academia novas formas de pensar a saúde e o cuidado. Construções discursivas relacionadas a experiências vividas que muitas vezes não se encaixam - e nem pretendiam se encaixar - na discursividade biomédica, produtora da normatividade nas práticas e nas produções de saberes. Linn da Quebrada (2017) escurece e enviadesce o tema quando nos lembra que foram homens, brancos, cis e heterossexuais que construíram e escreveram os livros de biologia, que disseram o que é história, que falaram quais são os valores que devem ser cultivados e que criaram e inventaram o conceito de cultura. Consequentemente, há muitos cis-temas a serem reconfigurados.

Sem surpresas, tais propostas, assim como qualquer proposta que se proponha a questionar estruturas normativas e (para)dogmáticas, produziram tensão, estranhamentos e resistências.

\section{Um respiro ciberespacial}

No dia 16 de julho de 2020 , o coletive abre os trabalhos para a segunda edição do evento. Já isolades, con-finades e distanciades, devido a epidemia da Covid-19, as possibilidades de realização de atividades se mostravam reduzidas. As reuniões antes recheadas de abraços, comidas, beijos e trocas foram adaptadas para conversas frente a uma webcam, um smartphone e um notebook. Fones de ouvido e microfones. Às vezes sem imagem, às vezes sem som. Faces travadas. Seu microfone está desligado. Vozes mudas. Quem abre a sala? Sai e entra de novo. Travou? Porém, esta era a única forma segura e possível de manter as reuniões e encontros do coletive. Ah, que saudades daquele café!

Cada tentáculo deste corpe lutava para manter sua produção, suas pesquisas e suas atividades em andamento, mesmo diante de tantas incertezas, frustrações, medos, inseguranças e perdas. Alguns de nós adoeceram. Uma precisou sair da cidade em que realizava seu trabalho de campo. Outros tiveram suas cargas intensificadas no trabalho ou nas relações domésticas.

Se no ano anterior Baphorau fez coisas de sarapantar, em 2020 só queria chorar. Queria respirar. Precisava de ar. Em meio a notícias constantes do número de mortos, 


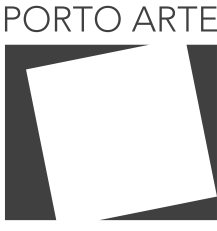

Revista de Artes Visuais

v.25 n 44

Jul/dez 2020 e-ISSN: 2179-8001

das chamas na floresta amazônica e as falas criminosas de chefes do executivo. Teríamos forças para produzir algo neste contexto? Sozinhas, talvez não. Mas os músculos deste cefalópode ainda podiam se movimentar. Mas haviam coisas que ainda precisariam ser repensadas. Como realizar um evento do /no corpo à distância? Não apenas a distância física se colocava como um obstáculo, mas também as habilidades tecnológicas para que uma live fosse possível. Era necessário aprender novas formas de se comunicar. Meet, Zoom, StreamYard, realidade virtual. Uma especialização intensiva em transmissão de imagem e vídeo no ciberespaço.

Assim ficou decidido que a segunda edição do Baphorau iria acontecer. E a ideia, desde as primeiras reuniões virtuais, era de homenagear aqueles que morreram durante a pandemia do novo coronavírus. O luto seria a força motriz. A memória de quem se foi se tornou aquilo que nos manteve de pé - ou, quase sempre, sentados na frente de algum gadget - e nos daria um motivo para suportar este momento tão desafiador.

A partir do trabalho de campo de uma das integrantes do coletive fomos informadas que uma mulher Baniwa de São Gabriel da Cachoeira (AM) comparou as mulheres daquela região a um cacto, porque o cacto é uma planta forte e resistente. Desta forma, o símbolo do evento deste ano seria um cacto. 0 cacto sobrevive a situações de extrema escassez. Possui espinhos para se proteger, mas ao mesmo tempo produz flores belíssimas para enfeitar os momentos de dificuldade. Éramos cactos também.

Assim como na versão anterior, o evento buscava dar protagonismos as pessoas que historicamente foram tidas como "objetos de estudo", que tem suas vidas, vivências e realidades consideradas como o "exótico", o "outro", "aquela a ser observada", mas quase nunca escutada. Não uma escuta horizontal. Ao pensar nos convidades que poderiam integrar o cronograma deste ano, buscamos em nossas próprias redes de relações aquelas que poderiam contribuir para a construção de novas possibilidades de olhares para a saúde, para pesquisas, projetos, corpes, enfrentamentos, artes e pensar para além dos lugares legitimados de saber (VERGUEIRO, 2012), ao passo que estas contribuições se tornariam resistências existenciais.

Nesse sentido, os dias 02 a 05 de novembro de 2020 foram intensos e imensos. Grandiosos em suas divisões, suas fronteiras e uniões. Os dias foram divididos em temas que se alinhavam às ideias que defendemos - no passado, presente e futuro - em um espaço tão tradicional como a Faculdade de Saúde Pública da Universidade de São Paulo (FSP/USP).

No canal oficial no youtube da FSP/USP ocorreu a abertura do tão esperado Baphorau. Neste dia, a presença virtual de integrantes do Departmentof Chicana and Chicano Studies da San Diego State University somou-se ao grupo do CPaS, alguns estudantes e professoras brasileiras da FSP/USP, para homenagear os imigrantes mortos durante a pandemia e verbalizar as alteridades em tempo de Covid-19. Uma celebração do Día de Los Muertos, um ato, uma homenagem, um encontro, que exalava resistência, luta, luto e afetos.

Nos dias seguintes, o Baphorau recebeu convidades que, a partir de suas (r)existências, tensionavam os conceitos de saúde, propunham as práticas relacionadas às identidades de gênero, sexualidades, corpes, raça, etnia e performatividades dissiden- 


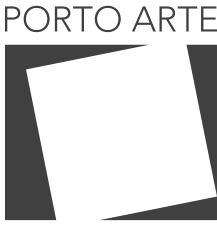

Revista de Artes Visuais v $25 n \cdot 44$ $\mathrm{Jul} / \mathrm{dez} 2020$ e-ISSN: 2179-8001

tes. Porque a partir das artes e das experiências seria possível repensar as potencialidades dos corpes e suas possibilidades de existir no mundo. Assim, mulheres indígenas, pessoas com deficiência, mulheres negras, pessoas trans, travestis, não bináries, fizeram do evento um espaço de florescimento e regeneração, em um ano onde tanto se perdeu, se queimou e se destruiu.

Dentro deste universo acadêmico, os ensinamentos e as disciplinas acabam por formar em seus pesquisadores um olhar disciplinado, fabricando e moldando a forma como se olha para nosso entorno (URIARTE, 2013). E quando nos deparamos com um isolamento social, a arte é o que nos permitiu ter esperança e ocupar nossos dias isolades, dentro de nossas residências. Mas se a arte (usando esta palavrinha aqui de forma vulgar e generalista) é tão importante assim, por que falamos tão pouco sobre ela dentre dos serviços e faculdades de saúde?

Produções artísticas e formatos diferentes de pensar a saúde, o corpo e a produção de saberes, contribuem para ampliar maneiras de enxergar (escutar e sentir) os movimentos sutis e corriqueiros dos sujeitos no mundo, e dando espaço e protagonismo para singularidades e expressões que muitas vezes não conseguem espaço dentro dos meios acadêmico-científicos. Além das falas "de fora" da academia, o evento como um todo se estruturou a partir de relações, em equipe, onde todes contribuíram de alguma forma para que o Baphorau pudesse se movimentar e lançar seus tentáculos mundo a fora.

Este pensamento com pessoas que vivenciam e produzem práticas em saúde e questões de cuidado, consequentemente, contribuem para repensar as definições do que é a Saúde Pública. Este Pensar-Com se conecta com ideias propostas pelas autoras Donna Haraway (2011) e María Puig De La Bellacasa (2012), "nestes incessantes movimentos de feitura de rede, a ontologia está continuamente no fazer, no processo de tornar-se-com", que faz, ininterruptamente tensionando as fronteiras e estabilidades através de práticas localizadas. Pensar-com (thinking-with) contribui para que artes, estudos históricos, ciências biológicas, práticas cotidianas e ativismos políticos se fortaleçam entre si, e permitam imaginar um mundo diferente, através da coletividade entrelaçada e um dissenso que produza cuidado.

0 evento teve diversas atividades e expressões diárias, seguindo a temática geral de "Luto, Luta e Memória": a abertura do evento que ocorreu no dia dois de novembro apresentou a live Duelo/Luto: alteridades em tempos de Covid19; nos dias seguintes, as lives realizadas estavam dentro dos temas, mais específicos: corpes e cores; Resistência indígena frente ao Coronavírus; Saúde, cura e ancestralidade; e como encerramento, no dia seis de novembro, produzimos um altar no Lahibrid da Faculdade de Saúde Pública em homenagem aos mortos de Covid-19. No entanto, iremos nos deter somente em dois dias de lives, a saber, corpes e cores e resistência indígena frente ao coronavírus e, na construção do altar, para comentar de forma breve o que estes pensar com, fora dos padrões científicos e hegemônicos produziram neste evento. 


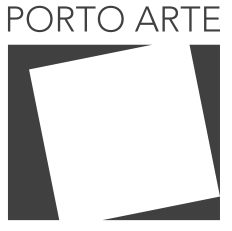

Revista de Artes Visuais

v $25 n .44$

$\mathrm{Jul} / \mathrm{dez} 2020$ e-ISSN: 2179-8001

\section{Produzindo-se}

No dia três de novembro, segundo dia de evento, tivemos como pauta a produção da arte como forma de autocuidado. Na live denominada "Ninho de desabafos: arte e saúde mental", o ilustrador de Salvador, Tomás Almansi, relatou como a arte permitiu que ele se "vingasse da realidade" que Ihe havia causado sofrimento. Seus quadrinhos, em suas palavras, permitiam que ele reformulasse os preconceitos que haviam lhe atravessado, se apropriando de falas e atitudes discriminatórias e reapresentando-as de uma forma irônica e com escárnio. Neste mesmo debate, Jonathan Macedo, estudante da ESALQ em São Paulo, expôs como suas próprias ilustrações permitiram que este colocasse para fora sentimentos e pensamentos que the causavam angustia e, como desenhar se tornou uma ferramenta essencial em seu processo terapêutico. Ele nos conta, por exemplo, como o simples fato de desenhar personagens com cachos, além de representativo, funcionou como um processo de autocuidado com sua saúde mental.

No dia seguinte, com temática indígena, contamos com a participação de Matheus Ribeiro na live "Coronavírus e violência: ilustrando cartilhas em contexto rionegrino". Matheus é Artista visual e muito reconhecido nas redes sociais, principalmente por suas ilustrações que denunciam violências contra povos originários, destruições do meio ambiente e a necropolítica do governo atual. Este artista produziu ilustrações para duas cartilhas produzidas para o Rio Negro, junto com o Departamento de MuIheres Indígenas do Rio Negro (DMIRN/FOIRN), Instituto Socioambiental (ISA) e a FSP.

A cartilha "Coronavírus (COVID-19) Tome cuidado, parente!", produzida em março, diz respeito às medidas de prevenções à Covid-19. 0 segundo material informativo "Violência doméstica e violência sexual em tempos de pandemia. Redes de apoio e denúncias: você não está sozinha!" foi realizado em julho, com o objetivo de reforçar algumas redes de apoio que as mulheres da cidade de São Gabriel da Cachoeira já tinham em relação às violências que sofrem.

Durante a live, Matheus evidencia a sensibilidade de seu trabalho ao contar como ele pensa a construção de seus desenhos. Mesmo estudando sobre populações indígenas e se preocupando com as questões de gênero, Matheus sempre se atentou em perguntar como eram as mulheres e crianças indígenas da cidade a qual estávamos trabalhando. Sua preocupação em compartilhar informações por meio das ilustrações era um posicionamento político. Além de informar e facilitar o entendimento, o artista procura em seus desenhos respeitar as especificidades daquela população e não seguir estereótipos padronizados, racistas e misóginos.

Após a produção deste material, as mulheres indígenas da cidade se organizaram para distribuir as cartilhas e conversarem sobre a questão de violências contra mulheres e crianças na cidade e nas comunidades indígenas. Além de grande repercussão do material na região do Rio Negro, também circulou pelo país por meio de lives realizadas pelas mulheres indígenas, por membra do CPaS, e com Matheus, no nosso evento bapho. 


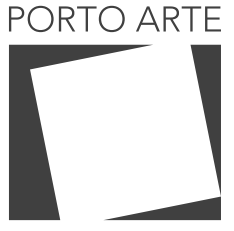

Revista de Artes Visuais

$\vee 25 n .44$

Jul/dez 2020 e-ISSN: 2179-8001

Além do trabalho realizado por Matheus, Elizângela da Silva de etnia Baré e Janete Alves de etnia Desana criaram e produziram literalmente saúde para os rionegrinos. Essas mulheres indígenas - participaram da live "produzindo vida frente ao fim do mundo: Rio Negro, nós cuidamos!" - são coordenadoras do DMIRN e criaram a campanha "Rio Negro, nós cuidamos!" que visa arrecadar e distribuir alimentos e máscaras para as pessoas de São Gabriel da Cachoeira e das comunidades indígenas. A ideia era que as pessoas pudessem ter esses materiais em suas casas já que, devido às barreiras sanitárias, não poderiam ir até a cidade para comprar alimentos ou vender seus produtos como geração de renda.

Elizângela e Janete, assim como outras mulheres de São Gabriel da Cachoeira, tiveram participações fundamentais em lidarem com a pandemia. Ademais, compartilhavam receitas de chás e benzimentos que utilizaram para a recuperação da nova doença e ainda, faziam a utilização de carro de som para auxiliarem as pessoas a se protegerem do novo vírus, contribuindo para o famoso achatamento da curva de mortos por Covid-19.

Essa omelete de relações, que produzem arte, que por sua vez constroem novas possibilidades de relações, é um instrumento pedagógico formidável, que permite que pessoas aprendam com a experiência do outro e assim repensem suas próprias concepções e práticas de cuidado.

A partir dos contatos de nossas redes, montamos um altar para homenagear os mortos durante a pandemia. A construção de um altar para celebrar os mortos, com muitas cores, muitas flores e um caráter festivo, faz parte dos costumes de muitos mexicanos.

Então, no dia 6 de novembro, último dia de evento, nos reunimos na FSP para montarmos um altar em memória dos mortos pela Covid-19. Momento que foi não apenas de produção de materiais para o altar em si e de homenagem àqueles que tiveram suas trajetórias interrompidas, mas também foi um momento de encontro. Muitos de nós nunca havíamos nos vistos pessoalmente. Alguns rostos das telas de computadores ganharam corpo, mais cor, calor, altura, cheiro.

0 altar, assim como o grupo e o evento, carregava seu hibridismo, com cores e estruturas inspirados na cultura mexicana, mas com elementos de nossas realidades, como esculturas de Orixás, artefatos e instrumentos produzidos por populações indígenas, ilustrações de mandacaru e imagens de outras religiões que integrantes do coletive fazem parte. Uma hibridização cultural, com os elementos da cultura mexicana e da cultura brasileira. Omolu (orixá invocada no Candomblé contra enfermidades), Nossa Senhora Aparecida (santa católica padroeira do Brasil) e Buda Shakyamuni (personificação do fundador do Budismo) dividindo e coexistindo no mesmo espaço, sem sobreposições ou justaposições, produzindo uma troca emocional, cultural, intelectual e artística. Essa polifonia representando não apenas o coletive, mas o que este grupo propõe para a produção de saberes na saúde, onde as práticas e os discursos existentes possam coexistir, contribuir entre si e assim elaborar novas possibilidades de existência. 


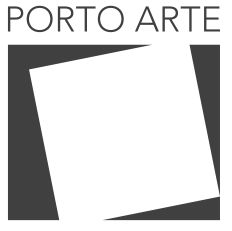

Revista de Artes Visuais

v. 25 ก. 44

$\mathrm{Jul} / \mathrm{dez} 2020$ e-ISSN: 2179-8001
Em meio a poesia, fotos, bandeirinhas, velas, sandálias, risadas, silêncios, mãos, pés e amor... encerramos a segunda edição do nosso evento baphônico.

\section{Reticências}

A arte pode ser entendida como relação de fluxos de intensidade e produção de afetos, outrossim, um meio de conexão de saberes. Uma encruzilhada de (r) existências, que se fazem necessárias para a construção de algo novo. A ciência de nada serve se estiver solitária em uma câmara de ecos. Se o discurso científico-acadêmico isolar-se da realidade que o rodeia e o atravessa, da alteridade inerente a toda e qualquer relação, ficará refém de sua homogeneização. E a ciência se oxigena com o plural e com a diferença.

Não propomos que as expressões artísticas substituam os discursos científico-acadêmicos, ou que haja uma inversão hierárquica entre estas produções, mas um reconhecimento mútuo de suas importâncias. 'Discordar de dentro' de nossos próprios compromissos - disciplinares, políticos, teóricos e éticos, como nos inspira Bellacasa (2012), pode contribuir para que novas formas de produção de arte e de ciência sejam possíveis. O reconhecimento destas formas de produção de saberes, estas possibilidades híbridas, também possibilitam que um maior número de corpes, experiências e vidas, participem ativamente das criações de novos olhares, novas teorias e novas práticas, como agentes e protagonistas.

$\mathrm{Na}$ Faculdade de Saúde Pública, outros grupos também buscam repensar a produção de saberes dentro da saúde, como é o caso do Coletivo Negro Maria Carolina de Jesus, que organiza anualmente o Outubro Negro dentro da universidade. Este ano, por exemplo, trouxeram apresentações artísticas, rodas de conversas e mesas de debate sobre as condições de vida e saúde da população negra, assim como os efeitos do racismo e a luta antirracista.

Assim como, em junho de 2018, o Centro Acadêmico Emílio Ribas (CAER) organizou um evento e uma intervenção questionando "onde estão as mulheres?", uma vez que todas as salas e auditórios da Faculdade de Saúde Pública recebem o nome de pesquisadores e professores homens (curiosamente, brancos e cis) da Saúde Pública no Brasil. As estudantes colaram nas portas das salas fotos de mulheres que foram importante para a pesquisa da Saúde Pública no Brasil, com uma pequena história de cada uma delas. No dia seguinte, estas impressões já haviam sido arrancadas.

Por fim, tomando café em casa e sem as companhias afetuosas de membros do coletive recordamos de Coral Macfarland Thuet, que nos encantou com sua simpatia, singeleza e voz durante a cerimônia de abertura: "no final das contas, quando há amor, sempre há esperança". 


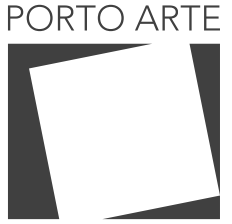

Revista de Artes Visuais

v. 25 n.44

Jul/dez 2020 e-ISSN: 2179-8001

Figura 1 - Exposição virtual realizada durante o evento através da plataforma do Google

Virtual Tour. Novas formas de

interação em um período de distanciamento físico.

Figura 2 - Exposição Tour Virtual "Respirando na cultura

em tempos de resguardo

Rio Negro, nós cuidamos!" disponibilizada no site do CPaS

1 durante o Baphorau. Essa

exposição foi criada por meio de imagens capturadas durante

a arrecadação, preparação,

transporte e entrega das

cestas básicas adquiridas

pela campanha Rio Negro, nós cuidamos! E por meio de relatos e áudios de mulheres indígenas

envolvidas com a campanha.
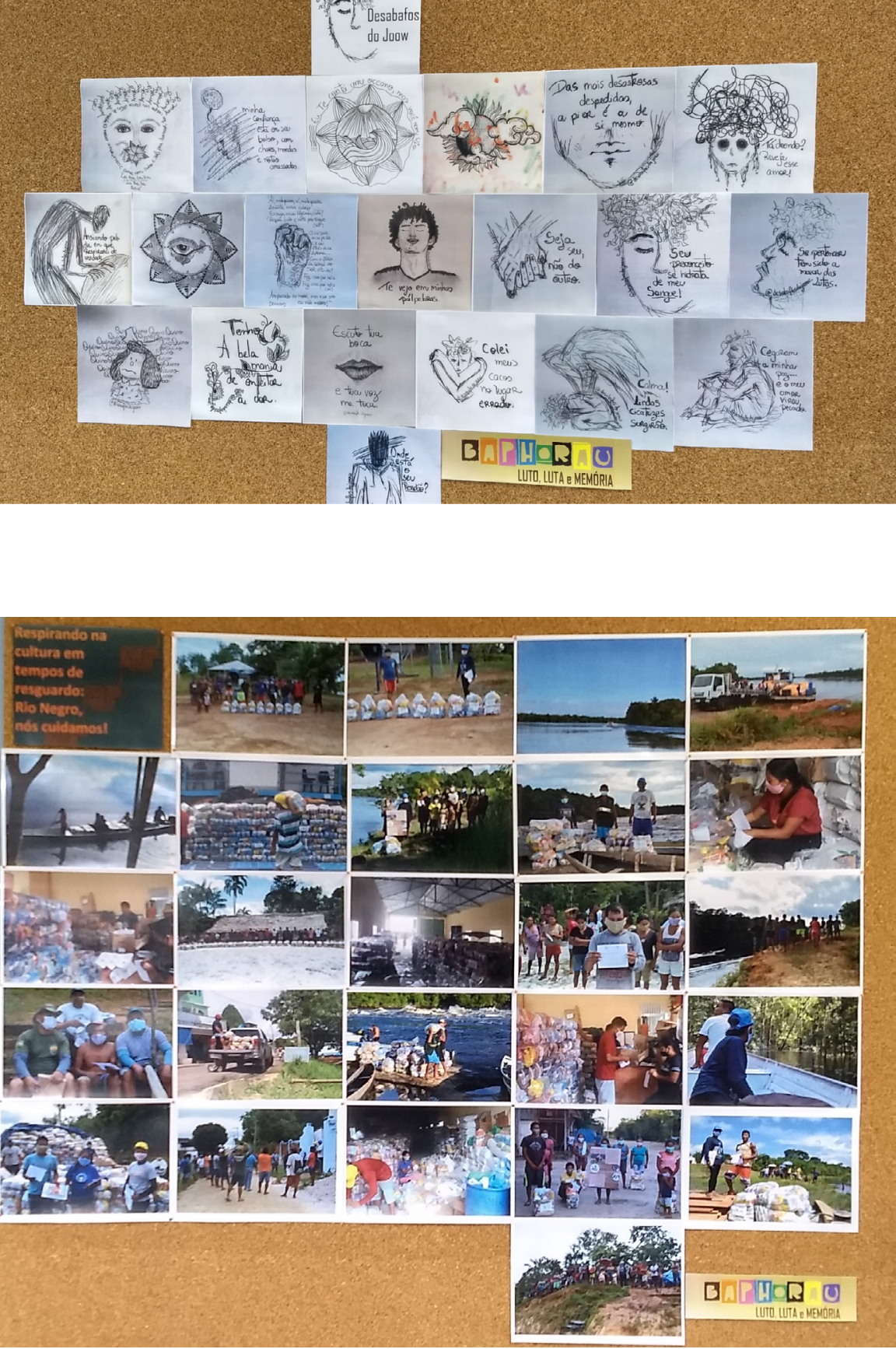


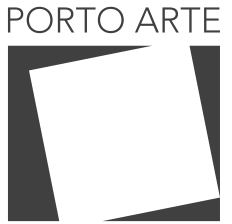

Revista de Artes Visuais

V. 25 ก. 44 Jul/dez 2020 e-ISSN: 2179-8001

Figura 3 - Berenice Cruz durante Live de abertura do Baphorau em homenagem aos imigrantes mortos durante a pandemia da COVID-19.

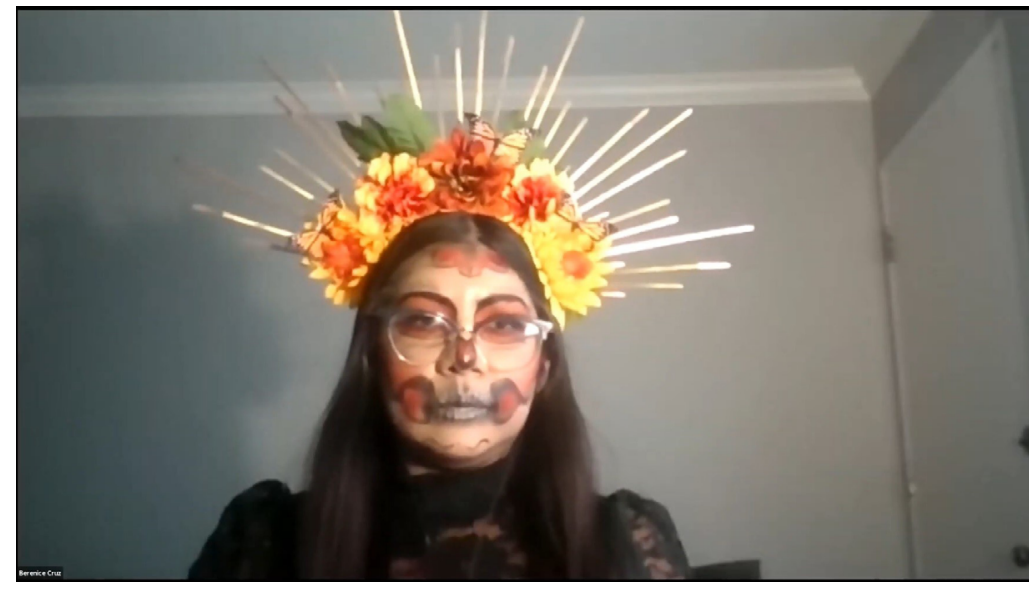

Figura 4 - Vídeo performance, "Meu corpo é minha casa" de Lissa Potter, durante a Mostra de Vídeos no Baphorau.

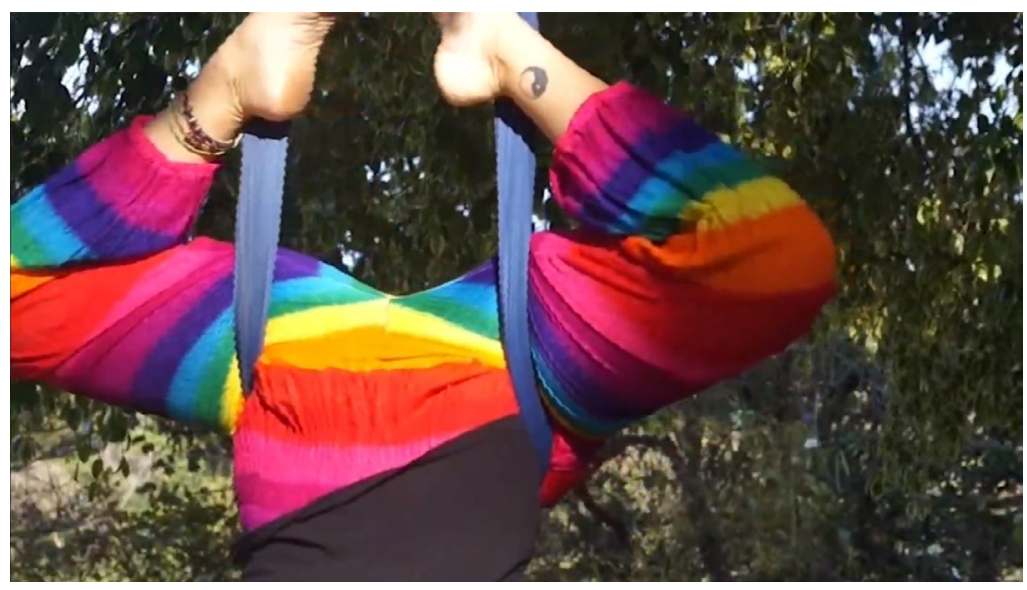




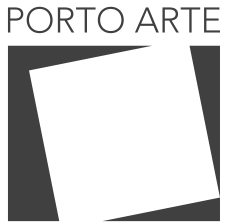

Revista de Artes Visuais

V. 25 ก. 44 Jul/dez 2020 e-ISSN: 2179-8001
Figura 5 - Encerramento de lives no dia cinco de novembro, com falas das convidadas Katia Martins e Cinthia dos Santos, e membros do CPaS-1.

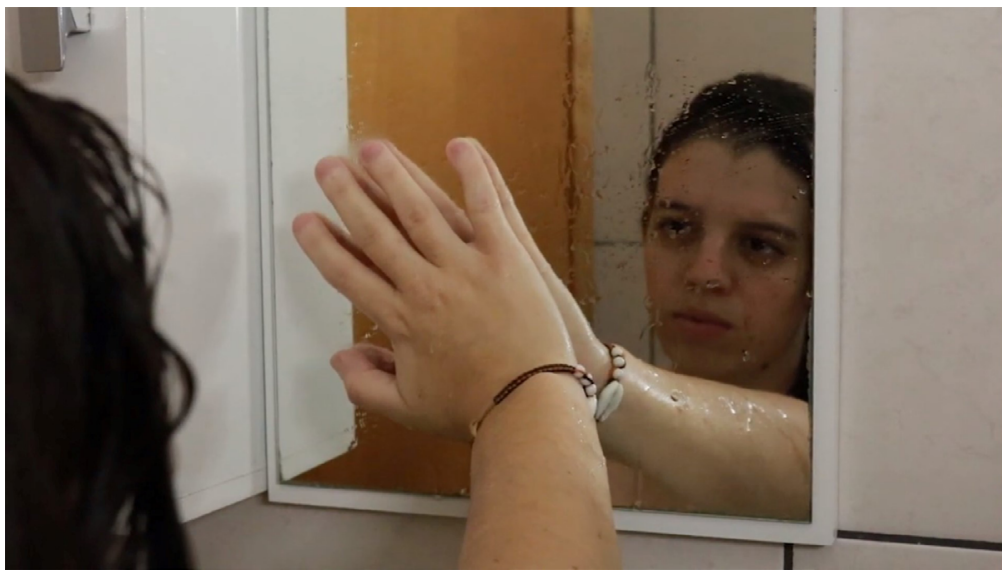

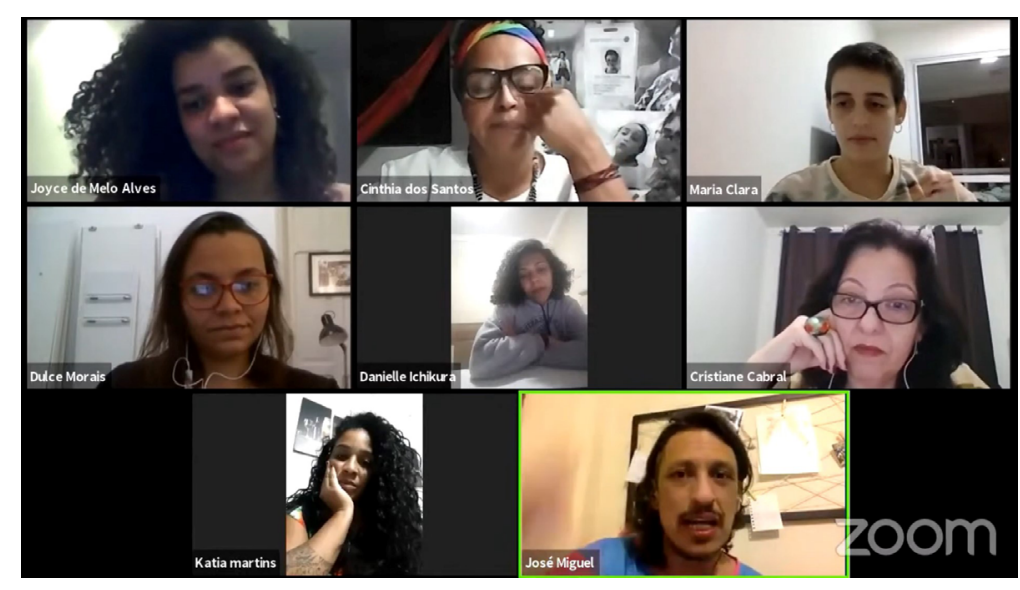

Figura 6 - Vídeo performance

"VAZIO", de Giulia Fagionato

Peira Ruffino e Xico Felipe

Pacheco da Silva, durante a mostra de vídeos do Baphorau. 


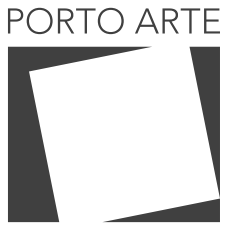

Revista de Artes Visuais

V. 25 ก. 44 Jul/dez 2020 e-ISSN: 2179-8001

Figura 7 - Altar montado no último dia do Baphorau, pelo CPaS-1.

Figura 8 - 0 altar foi feito com objetos de pessoas que morreram durante a pandemia da COVID-19 e com imagens que representação as diversas formas de fé da esperança, da morte e da cura.
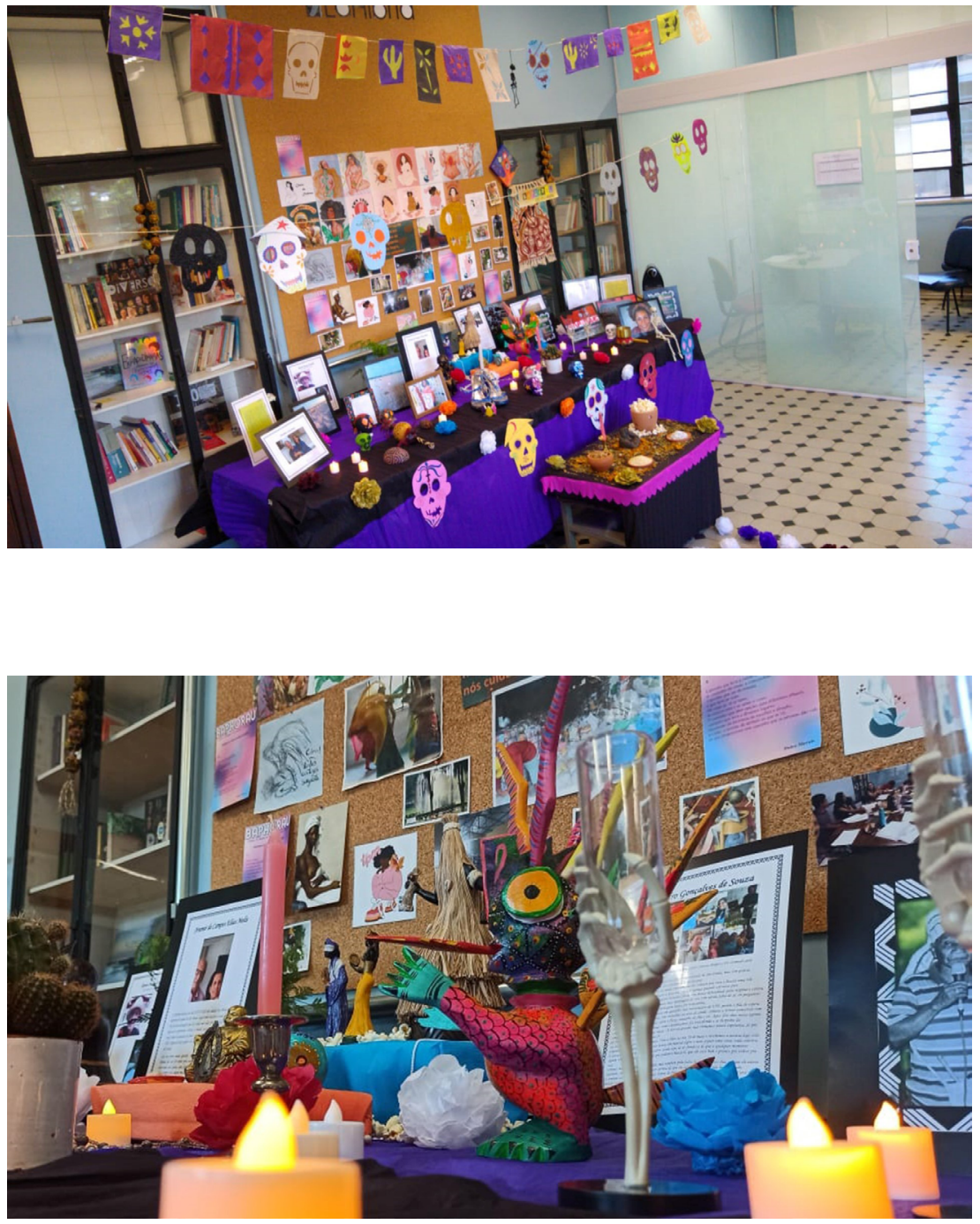


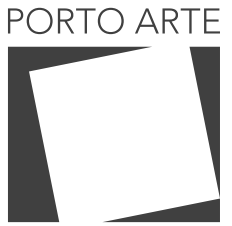

Revista de Artes Visuais

V. 25 ก. 44 Jul/dez 2020 e-ISSN: 2179-8001

Figura 9 - Através das redes sociais e e-mail, o CPaS-

1 recebeu mensagens de pessoas que perderam entes queridos durante a pandemia da COVID-19, que foram homenageadas no altar. A memória e o luto daqueles que partiram, mas que permanecem aqui.

Figura 10 - A travesti fármaco possuída, Pisci Bruja, durante a Live "Corpes e Cores" sobre a potência de corpes travestis:

"Eu entendo a arte como um local de potência".
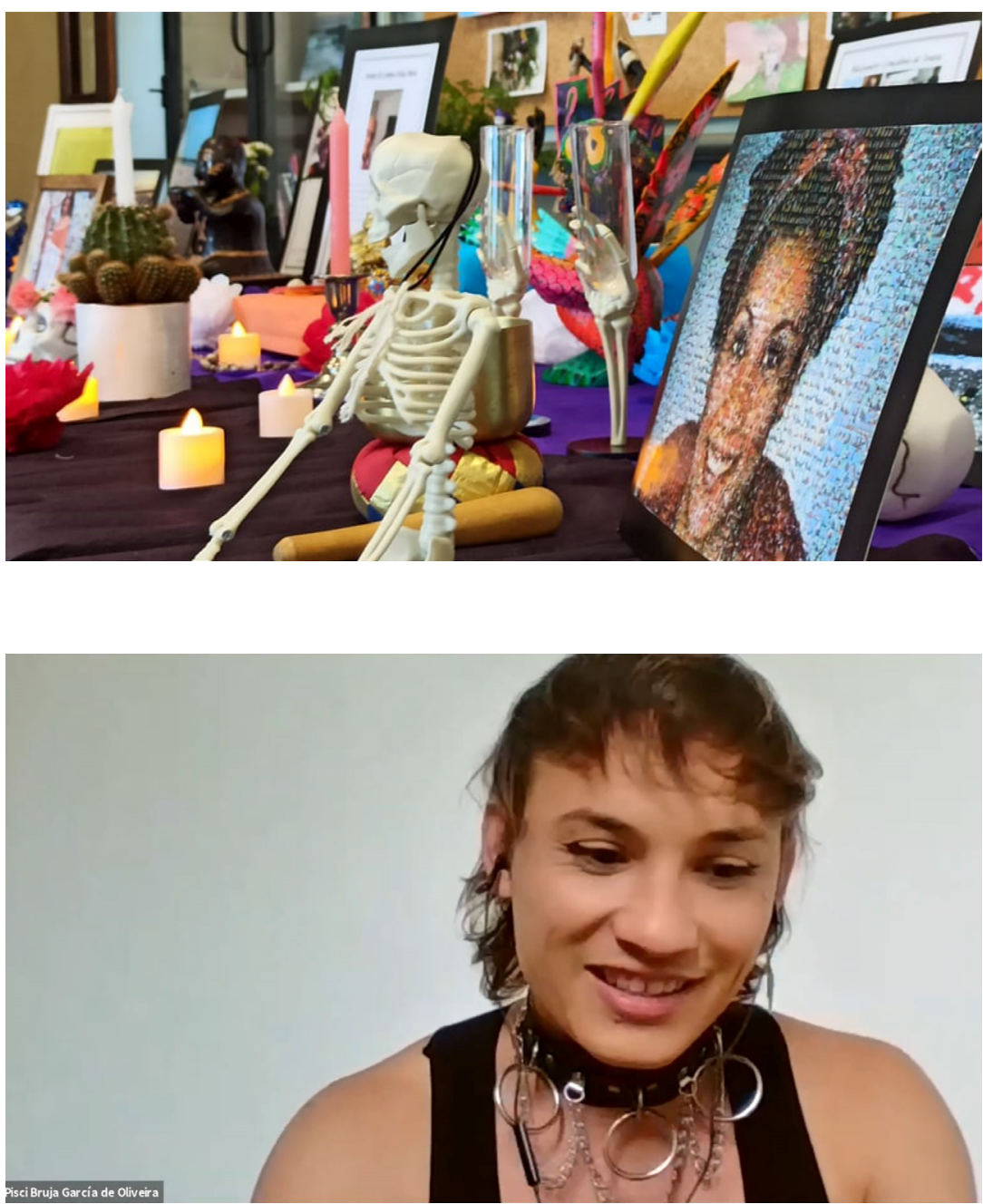


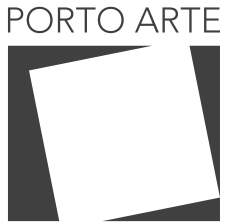

Revista de Artes Visuais

V. 25 ก. 44 Jul/dez 2020 e-ISSN: 2179-8001

Figura 11 - CPaS-1 no Laboratório de Hibridação científico-política em Saúde Pública, durante a produção do altar no dia 6 (seis) de Novembro.

Entre angústias, incertezas e medos, estar em relação nos mantém respirando.

Figura 12 - Coral Macfarland canta Yovengo a ofrecer $m$ corazónde Fito Páez durante a abertura do Baphorau. "¿Quiéndijo que todo está perdido? Yovengo a ofrecer mi corazón", em homenagem aos mortos durante pandemia do COVID-19.
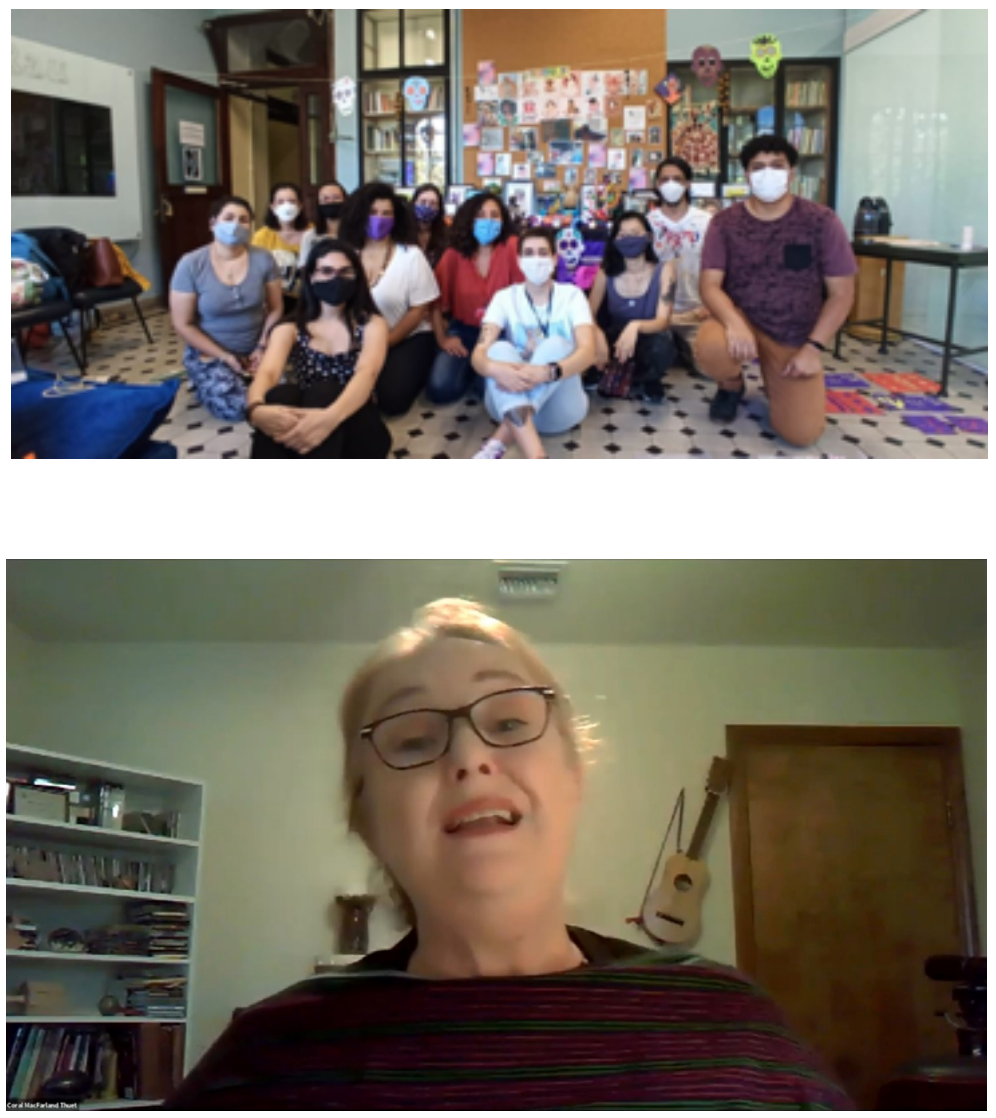


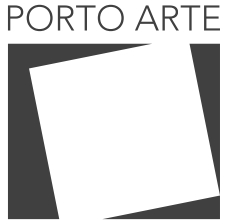

Revista de Artes Visuais

V. 25 ก. 44 Jul/dez 2020 e-ISSN: 2179-8001
Figure 13 - Altar montado pela professora Norma IglesiasPietro (SDSU - Department of Chicana and Chicano Studies), para homenagear os imigrantes, profissionais da saúde e profissionais do sexo mortos durante a pandemia da Covid-19, exibido durante abertura do Baphorau.
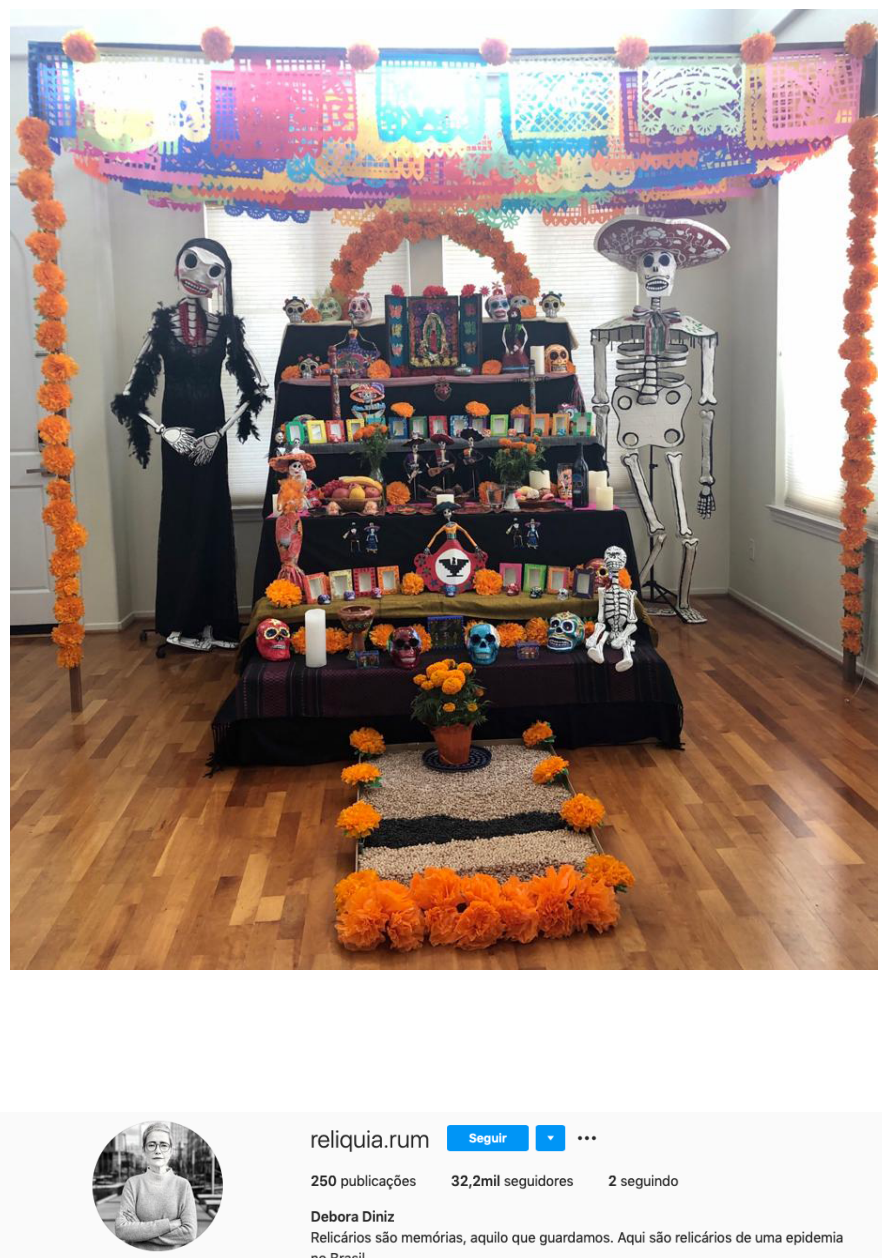

Debora Diniz

Relicários são memórias, aquilo que guardamos. Aqui são relicários de uma epidemia no Brasil.

Seguido por cartografilaefeto, ginecologiafeminista, paola_marugan e outras 1 pessoas

Figure 14 - Print da página do projeto Reliquia.Rum, idealizado pela professora Débora Diniz, convidada que participou da abertura do Baphorau. 


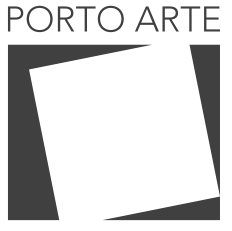

Revista de Artes Visuais

v. 25 n. 44 Jul/dez 2020 e-ISSN: 2179-8001

Figura 15 - Reliquia.Rum Transformando números em nomes. Relicários daquelas que foram vítimas da Pandemia do Covid-19. Print de uma das postagens do projeto da professora Débora Diniz.

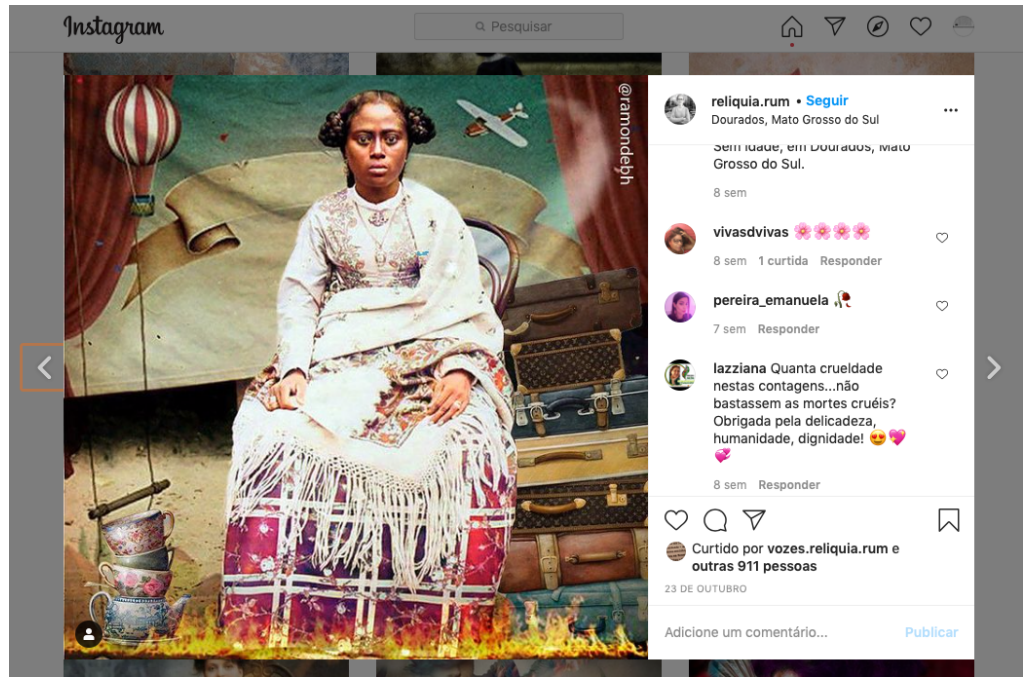

\section{Referências}

DE LA BELLACASA, María Puig. 'Nothing comes without its world': thinkingwithcare. The Sociological Review, v. 60, n. 2, p. 197-216, 2012.

HARAWAY, Donna. A partilha do sofrimento: relações instrumentais entre animais de laboratório e sua gente. Horizontes antropológicos, v. 17, n. 35, p. 27-64, 2011.

HOOKS, Bell. Postmodernblackness. PostmodernCulture, v. 1, n. 1, 1990.

QUEBRADA, Linn da. Linn da Quebrada: 0 'cis-tema' só valoriza os saberes heterossexuais.[Entrevista ao portal Universa]. 08ago. 2017. Disponível em:https://revistacult.uol.com.br/home/entrevista-linn-da-quebrada/. Acesso em: 1 dez 2020.

RESTREPO, Eduardo; ROJAS, Axel. Inflexióndecolonial: fuentes, conceptos y cuestionamientos. Colombia:Popayãn: Universidaddel Cuenca, 2010.

URIARTE, Urpi Montoya. Olhar a Cidade. Contribuições para a Etnografia dos Espaços Urbanos. Ponto Urbe. Revista do núcleo de antropologia urbana da USP, n. 13, 2013.

VERGUEIRO, Viviane. Por inflexões decoloniais de corpos e identidades de gênero inconformes: uma análise autoetnográfica da cisgeneridade como normatividade. Programa de PosGraduacao em Cultura e Sociedade, Universidade Federal da Bahia, Salvador, BA, Brasil, 2015. 


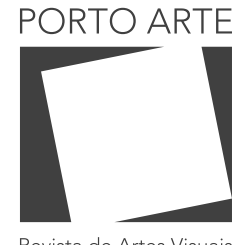

$\vee 25,44$ Jul/dez 2020 e-ISSN: 2179-8001

Texto submetido em: $21 / 12 / 2020$ Texto publicado em: 22/12/2020

\section{José Miguel Nieto Olivar}

Professor da Faculdade de Saúde Pública da Universidade de São Paulo (FSP/ USP). Doutor em Antropologia Social. Integrante do Laboratório de Investigação em Migração, Nação e Região de Fronteira (LIMINAR-UNIFESP) e do Observatório de Gênero do Amazonas (UFAM). Coordenador do Laboratório de Hibridação Científico-Política em Saúde Pública (LaHibrid) e do Coletive de Pesquisa em Antropologia e Saúde (CPaS-1). Colaborador da Rede Brasileira de Prostitutas. Pesquisador das áreas de Antropologia, Gênero e Sexualidade

\section{Michel de Oliveira Furquim}

Psicólogo. Mestrando em Saúde Pública pela Faculdade de Saúde Pública da Universidade de São Paulo (FSP/USP). Integrante do Coletive de Pesquisa em Antropologia e Saúde (CPAS-1) e do Instituto Pró-Diversidade. Atua e desenvolve pesquisa junto da população trans e travesti na cidade de São Paulo.

\section{Dulce Meire Mendes Morais}

Mestranda em Saúde Pública na Faculdade de Saúde Pública da Universidade de São Paulo (USP) e desenvolve pesquisa sobre violência sexual, mulheres indígenas, documentos e Estado na Amazônia urbana. Graduada em ciêåncias sociais com ênfase em antropologia pela Universidade Federal de São Carlos (UFSCar), especialista em saúde coletiva pelo Instituto de Saúde.

\section{Maria Clara Elias Polo}

Doutoranda em Saúde Pública pela Faculdade de Saúde Pública da USP. Membra do Coletive de Pesquisa em Antropologia e Saúde e do Grupo de Pesquisa sobre Gestão do Esporte, Lazer e Saúde (FAEFI/UFU). Graduação em bacharelado e licenciatura em Educação Física pela Universidade Federal de Uberlândia (UFU). Mestre em Educação Física pela Universidade Federal do Triângulo Mineiro. 